\title{
Medical Cover for Exercise Snow Queen 81/82
}

\author{
Capt C R Stephens* \\ $M B, B S, R A M C$
}

RMO 3rd Armd Div HQ and Signal Regt, B.AOR

Exercise Snow Queen is an annual 1 (BR) Corps exercise. It takes place in the Oberallgau area of Bavaria and this year is the nineteenth exercise. During the four month exercise a total of 8,500 troops are trained in the basics of alpine and langlauf skiing as well as winter survival. About 1.300 men pass through each two week course and there are about 300 permanent staff.

The Medical Detachment was based with the HQ, REME and RMP Detachments in the town of Sonthofen. Medical cover had to be provided for the HQ and Administrative Detachments and some $50 \mathrm{ski}$ huts scattered over the Oberallgau. The huts housed between 25 and 60 men and were between $5 \mathrm{~km}$ and $100 \mathrm{~km}$ away from the Medical Detachment.

The Medical Detachment consisted of a medical officer, a sergeant, four medical assistants and four drivers RCT. We had two landrover ambulances, a white Bedford ambulance and a GS landrover

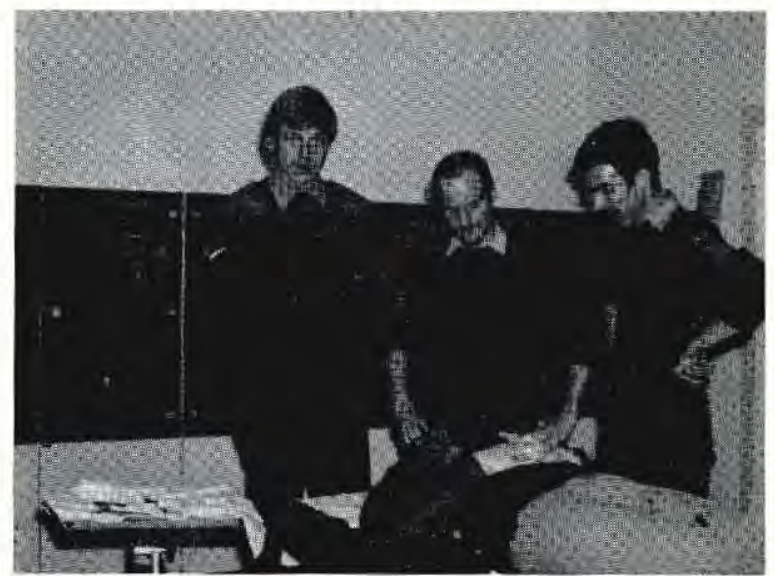

Part of the Medical Team

Apart from myself all the men and vehicles came from 2 Armd Div Field Ambulance. We were tasked with providing a 24 hour emergency service. The Detachment worked from Sanzentrum 617 in

*Now RMO 7 RHA the General Oberst Beck Kaserne in Sonthofen. A Sanzentrum is a large Medical Reception Station and consists of a number of consulting rooms, a large treatment room, $X$ ray facilities, a POP room and a 30 bed ward. It is stafted by four medical officers and a dentist under the command of a medical Lt Colonel. Also there are three nurses, three secretaries, two Medical Administrative officers and about 40 medical assistants. We were very dependent on the Bundeswehr and fortunately we integrated with them well. They gave us access to all their facilities but we provided our own drugs? and stationery. The Germans were quite happy for us to use their drugs but I found that though their drugs were similar to ours many consisted of a large therapeutic cocktail, for example an injection containing Dexamethasone, Phenylbutazone, Lignocaine and Vitamin B12 was used for backache. I preferred to use the drugs with which I was familiar.

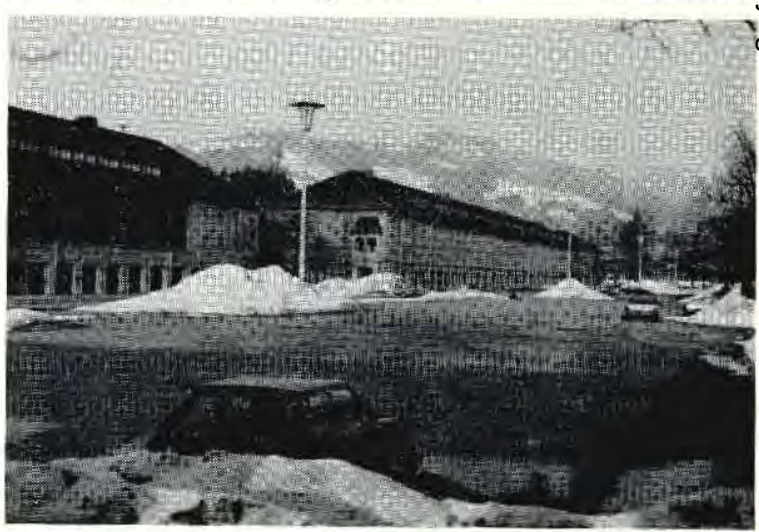

General Oberst Beck Kaserne

Each morning we did a combined ward round of the English and German patients in the Sanzentrum. After this from 9 till 11 a.m. I held sick parade. Here all the routine sick were seen. We could despatch ambulances to pick up patients from the ski slopes. The weather conditions varied but were sometimes quite severe though the ambulances had few problems with their four wheel drive and snow chains. 
The General Oberst Beck Kaserne is a training barracks for the Feld Jager (German Military Police). I lived in a room in the officers block. The rest of the Detachment shared part of a barrack block next to the RMP Detachment. Messing was with the Bundeswehr. The food was very different but after $3 \frac{1}{2}$ months one can get used to sausages and sauerkraut with peppermint tea.

Liaison with the Bundeswehr was good at all levels. Three of the German doctors spoke quite good English. All the doctors apart from the Lt Colonel were doing their 15 months national service. Professionally they found army medicine boring. They had little work to do and they saw only soldiers, many of whom came sick with very minor illnesses. This resulted in the German doctors being quite happy to see my patients if I was away visiting our soldiers who had been admitted to civilian hospitals.

The Bergwacht were available for the evacuation of the injured off the alpine slopes. These are volunteers who are all trained in first aid and mountain rescue both in summer and winter conditions and they do an excellent job. If a British soldier was injured, provided life was not in danger, they would radio their headquarters in Kempten, they would ring us at the medical centre and we would despatch an ambulance to the slope. During the exercise we had 37 call-outs to the slopes. There is an efficient German emergency service consisting of both ambulance and helicopter rescue as well as 'Notartz wagons.' These cars will bring the doctor and his equipment to the accident site where he will give immediate resuscitation to the injured.

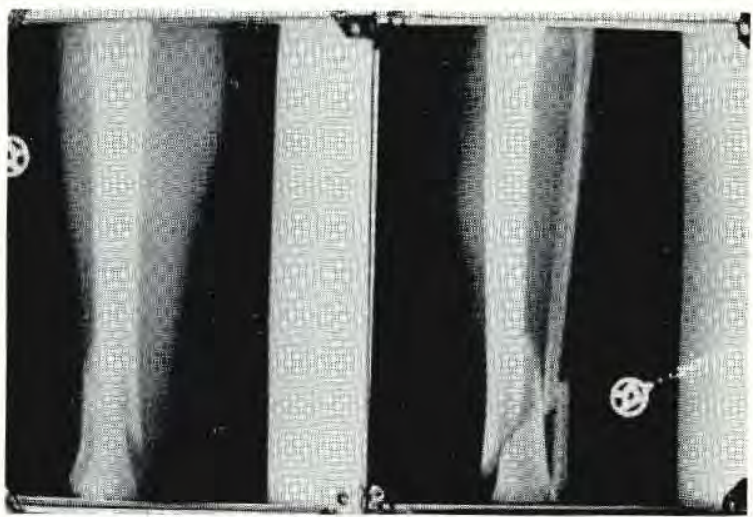

A typical spiral fracture of the tibia and fibula

Most of the hospitals in the area were used but mainly Immenstadt and Sonthofen, where 1 got to know the junior staff and some of the Consultants quite well. Most of the hospitals were modern and

well equipped and they have general surgeons who are experienced in orthopaedics. The German suro geons in this area follow the Swiss teaching oq internally fixing fractures, either by wiring them of plating them. A typical spiral fracture of the tibie caused by indirect violence, such as a sudden rotational force caused by catching the ski tip whe travelling at speed, is treated by open reduction of the fracture with internal fixation followed by $\frac{\mathcal{E}}{\Phi}$ 10 day stay in hospital, then gradually increase weight bearing over the next three months. Afte a year the plate is removed. The disadvantage of this technique is that two operations are required? and if infection occurs there is a risk tha. $\vec{P}$ osteomyelitis may result. Eight soldiers fractured their tibia and fibia, one bilaterally. Thirty soldier were admitted to civilian hospitals and there werk 27 casualty outpatients consultations. One hundre and thirty nine patients were admitted to the war $\mathbb{\Phi}_{\text {}}$ of the Sanzentrum.

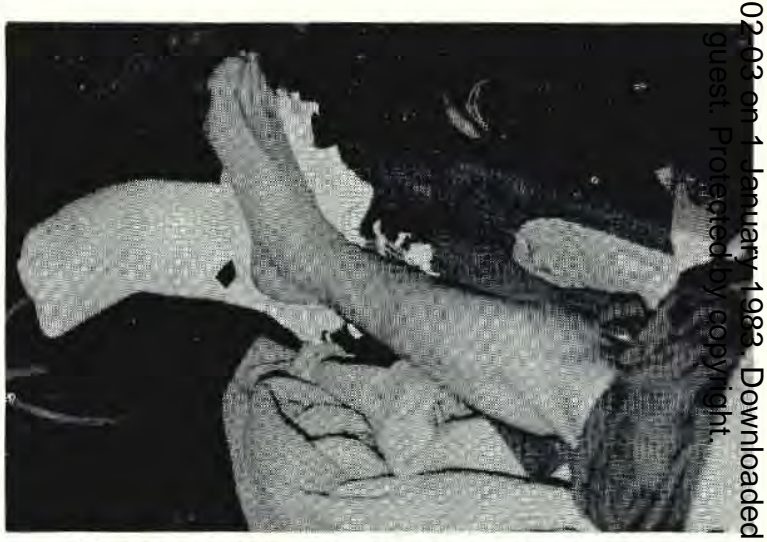

Fractured tibia showing some swelling and deformity

Soldiers requiring evacuation from the exercis were admitted to the Sanzentrum either after theik injury or when discharged from hospital. From the Sanzentrum they were evacuated either by road o⿸\zh14⿰⿺乚一匕 rail or air depending on their injury. Most patients were evacuated to BMH Hannover some 500 miles away. There were weekly coach runs northwar which were suitable for walking wounded an of treated leg fractures. The journey takes about $1(\mathbb{\Phi}$ hours. There is a direct rail link from Sonthofen ti Hannover. Thirteen casualties were evacuated this way accompanied by an escort. A whole comparto ment could be reserved in advance.

Evacuation by air for stretcher cases was eithero direct from the barracks by an Army Air Corps. Lynx helicopter or by an RAF fixed wing aeroo plane from Memmingen Luftwaffe airfield 600 $\mathrm{Km}$ up the motorway. Four stretcher cases were evacuated by each method. 


\section{R Stephens}

The most frequent cause of reporting sick was injury. The most common skiing injury was a strain of the medial ligament of the knee. This not only produced localised tenderness but also limited flexion and an effusion. Such an injury tended to prevent the soldier skiing for at least a week, often longer, particularly as parallel turns while skiing put considerable stress on the medial ligaments. The majority were caused by attempting too difficult slopes too early, and often there was failure of the ski bindings to release. The novice skier is particularly liable to this injury as when he falls over he tends to straighten the leg preventing any rotation and thus making injury to the ligaments inevitable. It is interesting to note that with the evolution of the ski boot from ankle high to mid calf ankle injuries have become less common. Lacerations were common and usually caused by the tips and edges of the ski. This tended to occur more frequently in the older type of ski, which, when the binding releases remains loosely tied to the skiers leg; as the soldier rolls down the slope the ski clips his head. The new ski bindings have a brake and are completely released from the skier. One injury to the groin was nearly fatal. It was caused by a soldier skiing into the back of a langlauf ski which hit his femoral artery. If prompt first aid had not been given, as well as swift evacuation by helicopter to a vascular surgeon, he might have died.

Hand and finger sprains were quite common. There were eighteen shoulder dislocations caused by falls while skiing. The majority were reduced after pethidine and diazepam were given intravenously. Quite a number of soldiers were seen who had recurrent dislocations and who had one or even two operative repairs. It is doubtful whether they should continue to ski. There were a number of fractured ribs but only one serious chest injury. This occurred when a racing skier travelling at high speed fell and hit his chest on a bank of ice. $\mathrm{He}$ fractured the majority of his right ribs and this caused a haemopneumothorax.

Upper respiratory tract infections were common as sore throats and flu tended to spread around a hut very quickly. The dental sick rate was also quite high with a number of dental abscesses being treated. A small number of families were seen ranging from antenatal through childhood illnesses.

Table I

Sick Parade Morbidity Ex Snow Queen 81/82

\begin{tabular}{llr}
\hline a & Respiratory & 166 \\
b & Alimentary & 74 \\
c & Skin & 79 \\
d & Injuries & 736 \\
e & Others & 101 \\
f & Dental & 46 \\
& Total Soldiers & 1096 \\
& Total Dependants & 76 \\
& Total Patients & 1172 \\
\hline
\end{tabular}

Table II

Fractures Ex Snow Queen 81/82

Lower Leg

Stove in Chest

Hands/Wrist

Arm

Clavicle

Shoulder dislocation

Nose

Spine

$\begin{array}{ll}19 \\ 1 & \\ 10 & \\ 1 & \\ 1 & \\ 1 & \\ 1 & \end{array}$

I enjoyed my time in Sonthofen with Exercise Snow Queen. I got to know another part of Germany and a lot of Germans, I learned to ski, my German improved as did my knowledge of orthopaedics and skiing injuries. Most of all I remember the welcome and hospitality given to our detachment by the Bundeswehr Medics. 